American J. of Engineering and Applied Sciences 2 (1): 54-60, 2009

ISSN 1941-7020

(C) 2009 Science Publications

\title{
Effect of Torsion on Externally Prestressed Segmental Concrete Bridge with Shear Key
}

\author{
${ }^{1}$ Algorafi, M.A., ${ }^{1}$ A.A.A. Ali, ${ }^{1}$ M.S. Jaafar, ${ }^{2}$ I. Othman, ${ }^{3}$ M.P. Anwar and ${ }^{1}$ R. Rashid \\ ${ }^{1}$ Department of Civil Engineering, Universiti Putra Malaysia, 43400 Serdang, Selangor, Malaysia \\ ${ }^{2}$ Department of Civil Engineering, University Of Malaya, 50603 Kuala Lumpur, Malaysia \\ ${ }^{3}$ Housing Research Centre, Universiti Putra Malaysia, 43400 UPM Serdang, selangor, Malaysia
}

\begin{abstract}
Externally Prestressed Segmental (EPS) concrete box sections are widely used in the construction of bridge structures today. EPS concept has become an attractive tool for rehabilitation and strengthening of existing bridges which have insufficient strength and/or excessive deflection and cracking. Problem statement: EPS bridges are affected by combined stresses (bending, shear, normal, and torsional) at the joint interface between the segments. However, very limited researchers studied this type of bridges under combined stresses. Approach: This paper presented an experimental investigation of the structural behaviour of EPS bridge with shear key under torsion. Four beams were tested, each containing three segments that were presetressed using two external tendons. A parametric study of two different external tendon layouts as well as different levels of torsional force applied by different load eccentricities was conducted. Results: The effect of torsion was evaluated in terms of vertical deflections, concrete and tendon strains, failure loads and failure mechanisms. It was concluded that torsion has a significant effect in the structural behaviour of external prestressed segmental box girder beams. Torsion not only alters failure load of the beam but also changes the type of failure mechanism. It was also investigated that harp tendon layout results in better structural behaviour in term of deflection and tendon strain as compared with the straight tendon. Recommendations: It recommended including the effect of joint (flat and shear key) type as well as the effect of tendon layout under torsion to obtain comprehensive behavior of EPS bridge.
\end{abstract}

Key words: Externally prestressed, segmental concrete bridge, combined stresses, torsion

\section{INTRODUCTION}

Externally Prestressed Segmental (EPS) concrete box bridges have been successfully designed and constructed all over the world. For the majority of these bridges, the prestressing tendons were fully bonded. Recently, unbounded external prestressing tendons have been used for this type of construction. External prestressing without bond has been used in bridge construction for many years. It is also a useful method for the rehabilitation and strengthening of existing structures.

The construction of segmental bridges with unbounded tendons offers some advantages such as: 1) Substantial economical savings due to the possibility of weather-independent segment production and a shorter construction period; 2) Simple element assembly at job site; 3) Replaceability of tendons and 4) Optimal corrosion protection of the prestressing tendons and improved fatigue behaviour.
The analysis of a concrete member with an unbounded external tendon is complicated because of the fact that strain compatibility of concrete and prestressing tendon at a section can no longer be applied. If friction is ignored, the force in the tendon is constant between the anchorages under all loads.

When the tendon is external, there is an additional difficulty due to the change in tendon eccentricity with applied loads. This change in eccentricity should be accounted for by considering the equilibrium of the structure at its deformed position. Since friction occurs only at deviators, the loss of tendon force due to friction is smaller compared to that in the internal tendons. When the applied load increases, the external tendon slips at deviators resulting in redistribution of the tendon force, which affects the displacements of the member. As mentioned earlier, the analysis of externally prestressed structure should also account for the cases where the tendon is bonded or unbounded at the deviators. This is because, in the case where the

Corresponding Author: Algorafi, M.A., Department of Civil Engineering, Universiti Putra Malaysia, 43400 Serdang, Selangor, Malaysia Tel: 0060176879179 Fax: 0060389467869 
external tendon is bonded at deviators, the force in the tendon is constant only between deviators, whereas when the tendon is unbounded (assuming no friction or free slip), the force in the tendon is constant along the entire length of the tendon between anchorages.

When a structure is constructed with precast segments assembled with external prestressing, the possible opening of the joints between the segments due to relatively high applied load should be considered in the analysis. Since internal reinforcements do not cross the joints, only external prestressing should carry the additional tension due to increase in loads. Thus, the force in the tendon is dependent on the magnitude of the joint opening.

Existing research on EPS bridges: Many investigations of segmental structures with external prestressing were carried out in the last few decades, but most of them were restricted to a load combination of bending and shear such as in the research carried out by ${ }^{[2,6,7]}$. Only a few investigations dealt with the influence of a combined loading of bending, shear and torsion on the behaviour of segmental structures such as by ${ }^{[3-5]}$ presented analytical model to investigate the behaviour of a prestressed segmental bridge with unbounded tendons under combined loading of torsion, bending and shear. A modified skew bending model was developed to calculate the load-carrying capacity of segmental bridges subjected to combined forces. It concluded that the ultimate bending and shear strength of monolithic and segmental girders were virtually the same. Only the torsional capacity of the segmental box girder was reduced.

Al-Gorafi et al. ${ }^{[1]}$ presented a detail review of the behaviour of prestressed bridges under combined stresses, with a particular emphasis on External Prestressed Segmental Bridges. It was concluded that a comprehensive analytical and experimental research on SEP bridges needs to be carried out under stresses resulting from combined bending, shear, normal and torsion forces.

\section{MATERIALS AND METHODS}

Experimental program: To investigate the effect of torsion on EPS box girder bridge with shear key, two series of beams (with different tendon layouts) with $3 \mathrm{~m}$ length were tested under vertical loading. Each beam had three segments (two symmetrical edge segments and one middle segment) as shown in Fig. 1. The dimensions and reinforcement details are shown in Fig. 2. Double 7 wires $\Phi 0.5$ inch strand external prestressed tendons (ASTM A 416-85 Grade 270) were used which were in contact with the beam at anchorages and deviator only (Fig. 1). The area of each tendon was 98.7 $\mathrm{mm}^{2}$. Table 1 shows the property of material, tendon layout and load cases in the different beams.

The effect of two different parameters were studied to investigate the load capacity, deformation characteristics, strain variation, failure load and failure mechanism of EPS bridges. One of them was tendon layout (straight and harp) and the other was torsion (imposed by providing eccentricity of $0 \mathrm{~mm}$ and 200 $\mathrm{mm})$.

Test setup and instrumentation: The assembly of beam was carried out by arranging the segments close together on temporary supports. After that the two prestressed tendons were laid through the anchorages and deviator.

Two thick steel plates $(600 \times 600 \times 20 \mathrm{~mm})$ were placed on the end of the edge segments. The steel plates were used to ensure a uniform distributed of prestress forces on the beams. Each beam was loaded with three point load with $2.4 \mathrm{~m}$ span length as shown in Fig. 3. The prestress load was applied using a jack of 30 ton capacity at each tendon; however the vertical load was applied using a jack of 50 ton as shown in Fig. 3.

The axial and vertical deformations were measured using LVDT as well as mechanical dial gauges placed at different location of the beam. The strain was measured by strain gauges fixed at each face of the beam at different location as shown in Fig. 4.

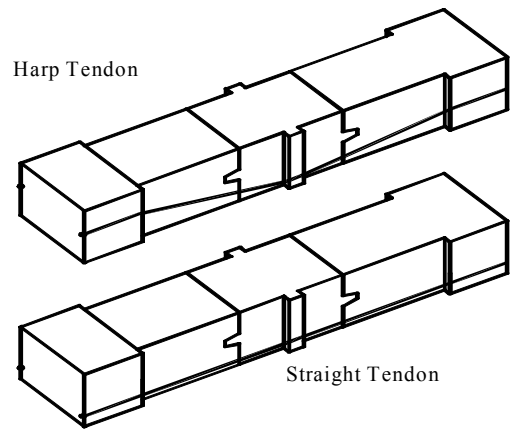

Beam
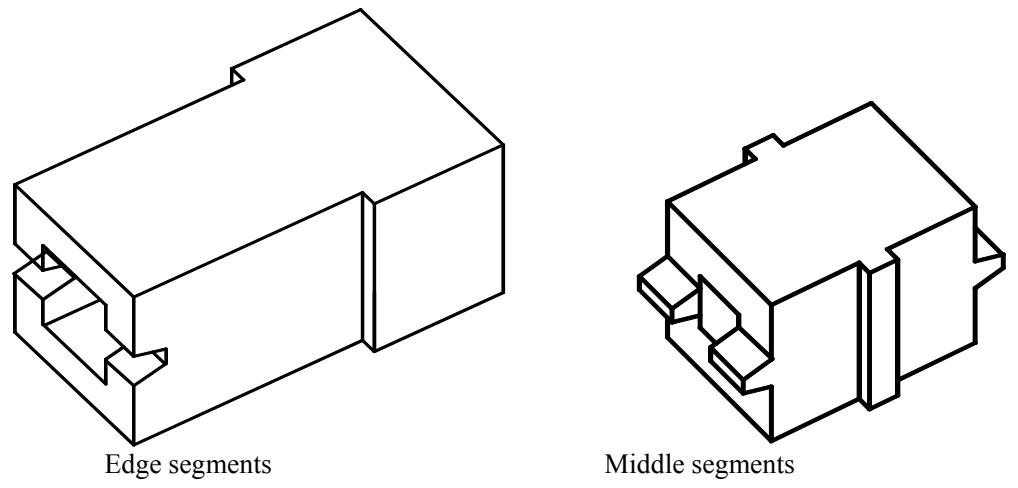

Fig. 1: Isometric view of beam and segments 
Am. J. Engg. \& Applied Sci., 2 (1): 54-60, 2009

Table 1: Property of materials, tendon layout and load case in test beams

\begin{tabular}{|c|c|c|c|c|c|c|c|c|}
\hline & \multicolumn{2}{|l|}{ Concrete } & \multicolumn{2}{|l|}{ Reinforcement } & \multicolumn{2}{|c|}{ Prestressed Tendon } & \multirow[b]{2}{*}{$\begin{array}{l}\text { Tendon } \\
\text { layout }\end{array}$} & \multirow[b]{2}{*}{$\begin{array}{l}\text { Load (mm) } \\
\text { eccentricity }\end{array}$} \\
\hline & $\begin{array}{l}\text { Compression } \\
\text { Strength (MPa) }\end{array}$ & $\begin{array}{l}\text { Modulus of } \\
\text { elasticity (MPa) }\end{array}$ & $\begin{array}{l}\text { Yield Strength } \\
(\mathrm{MPa})\end{array}$ & $\begin{array}{l}\text { Modulus of } \\
\text { elasticity (MPa) }\end{array}$ & $\begin{array}{l}\text { Yield Strength } \\
\text { (MPa) }\end{array}$ & $\begin{array}{l}\text { Modulus of } \\
\text { elasticity (MPa) }\end{array}$ & & \\
\hline $\mathrm{C} 1$ & 46 & 340000 & 420 & 2000000 & 1700 & 1950000 & straight & $\mathrm{e}=0$ \\
\hline $\mathrm{C} 2$ & 49 & 350000 & 420 & 2000000 & 1700 & 1950000 & straight & $\mathrm{e}=200$ \\
\hline D1 & 46 & 340000 & 420 & 2000000 & 1700 & 1950000 & harp & $\mathrm{e}=0$ \\
\hline D2 & 49 & 350000 & 420 & 2000000 & 1700 & 1950000 & harp & $\mathrm{e}=200$ \\
\hline
\end{tabular}

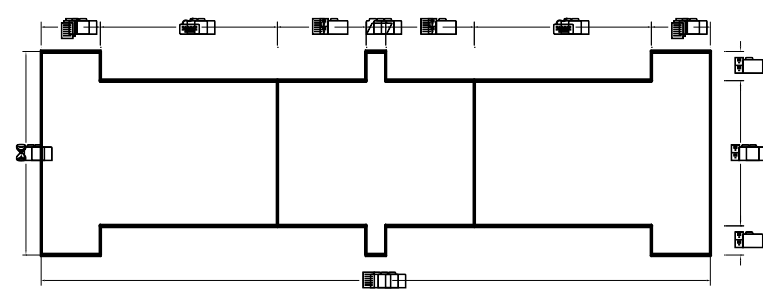

(a) Plan View of Beam

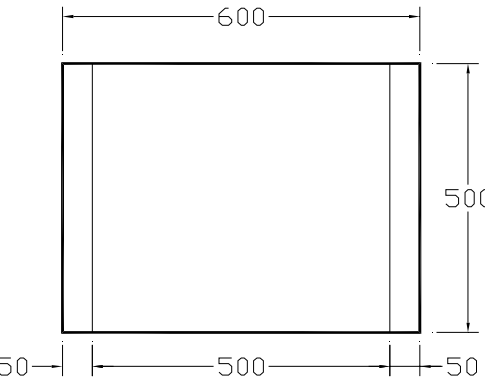

(c) End View of Beam

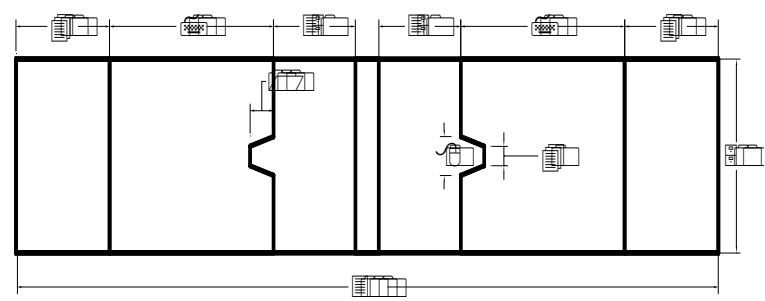

(b) Side View of Beam

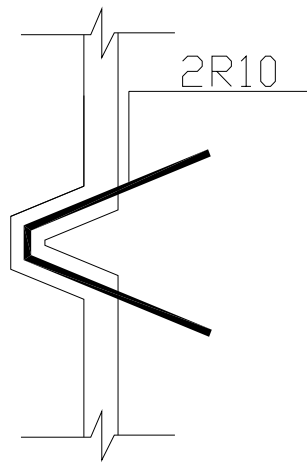

(d) Shear Key Reinforcement

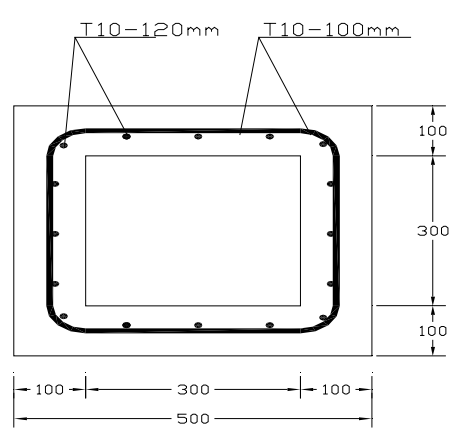

(e) Reinforcement of beam

Fig. 2: Dimension of beams and reinforcement (all dimensions in $\mathrm{mm}$ )
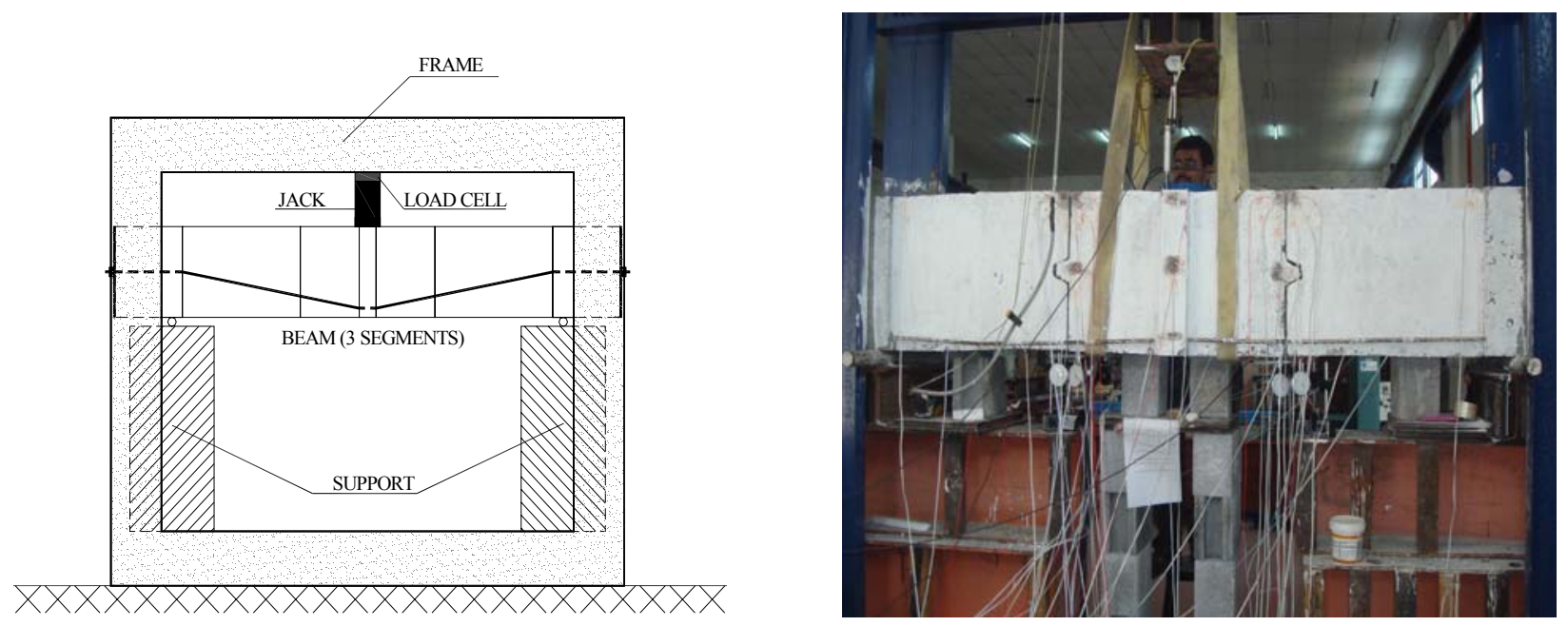

Fig: 3 Test Setup of the Beam 


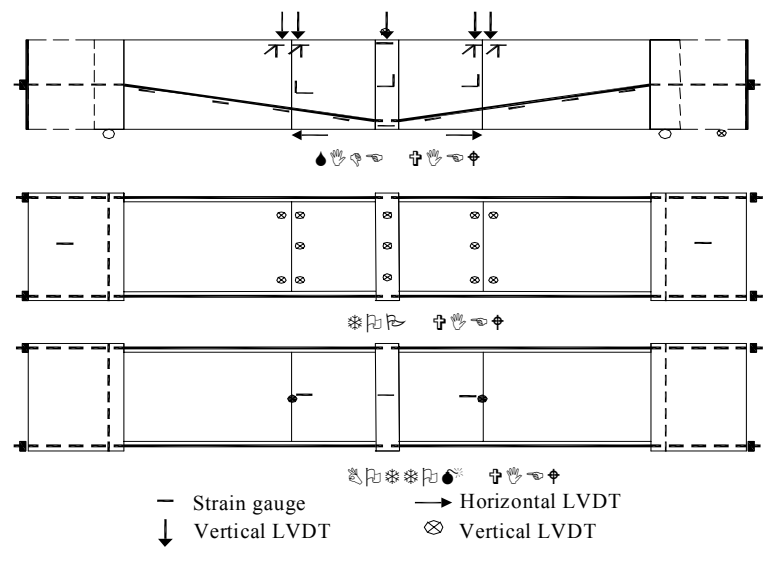

(a) Transducer arrangement

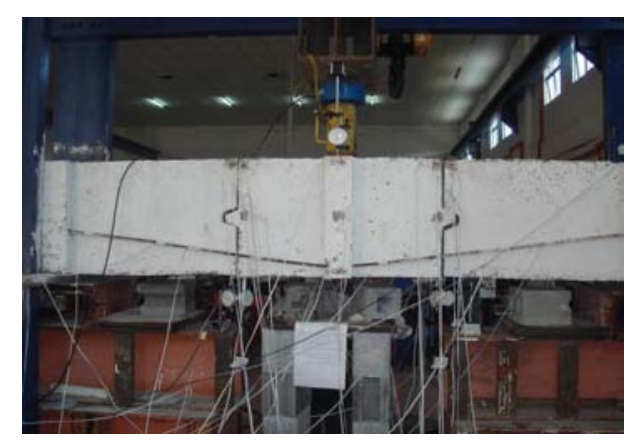

(b) Typical experimental setup for test beam

Fig. 4: Transducer arrangement and typical experimental setup for test beam

\section{RESULTS and DISCUSSION}

Structural response: Initially, low prestressed load was applied to remove the temporary supports. All beams were prestressed until approximately 2200 Micro strain (which is equal to one third of yield strength of tendon). Then the vertical load was applied gradually until failure. The behaviour of the beams were evaluated in terms of vertical deformation, twist angle, opening between segments, tendon strain, load capacity, failure mode and shall be discussed in subsequent sections. It needs to mention that the ultimate load of beam D1 could not be recorded as the support failed before the beam failure.

Table 2: Summaries of deflection characteristics of all beams

\begin{tabular}{lrrrr}
\hline & $\mathrm{C} 1$ & $\mathrm{C} 2$ & $\mathrm{D} 1$ & \multicolumn{1}{c}{$\mathrm{D} 2$} \\
\hline Load at onset point of nonlinearity $(\mathrm{kN})$ & 50 & 10.000 & 55 & 20.000 \\
Ultimate load (kN) & 206 & 159.000 & $161^{*}$ & 150.000 \\
Ultimate Deflection (mm) & -31 & -21.600 & $-24^{*}$ & -24.600 \\
Maximum twist (rad) & & 0.063 & & 0.071 \\
Load at opening (kN) & 50 & 10.000 & 55 & 20.000 \\
\hline * The ultimate load of beam D1 not exist & & &
\end{tabular}

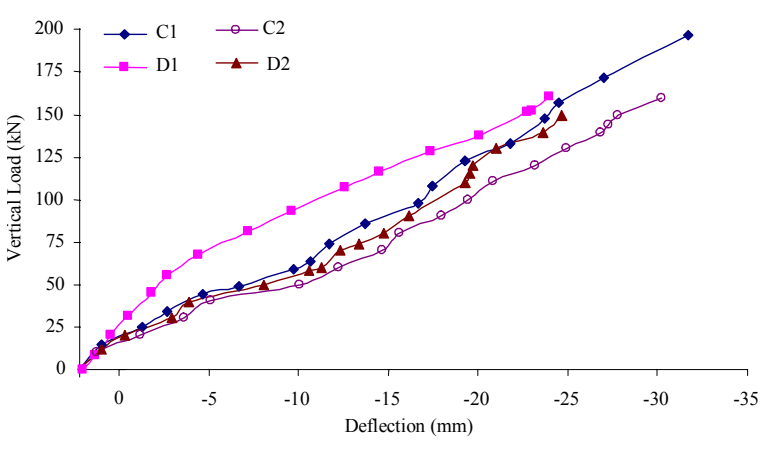

Fig. 5: Central deflection for beams $\mathrm{C}$ and $\mathrm{D}$

Deformation characteristics: Figure 5 shows the loadvertical deflection curves at mid span for different types of beams. Initially the relationship is linear and with further increase of applied load, the response becomes nonlinear until failure.

In case of beams $\mathrm{C} 1$ and D1 (without load eccentricity), the relationship was linear up to vertical load of $55 \mathrm{kN}$ and $50 \mathrm{kN}$ respectively. After that, the response was nonlinear up to $200 \mathrm{kN}$. Finally the middle segment suddenly dropped due to a sliding failure.

In the case of C2 and D2 beams $(200 \mathrm{~mm}$ load eccentricity), the relationship was linear up to $20 \mathrm{kN}$ and $10 \mathrm{kN}$ respectively which were lower than that of $\mathrm{C} 1$ and D1 beams. After that, the response was nonlinear until the middle segment failed at a vertical load of approximately $150 \mathrm{kN}$. This failure resulted from the gradual increase in twist. Therefore, it can be concluded that torsion reduced the linear portion.

In addition, it can be concluded that the overall stiffness of beams D1 and D2 (harp tendon) were higher than that of beams $\mathrm{C} 1$ and $\mathrm{C} 2$ (straight tendon) because in the case of D1 and D2, the vertical component of tendon force resisted the vertical load.

Table 2 summaries the load and vertical deflection at onset point of nonlinearity and ultimate load for the beams. It is evident that torsion reduces the vertical load and the vertical deflection at onset point of nonlinearity as well as at ultimate load. On the other hand, no significant differences between the ultimate load capacities for different tendon layouts were observed because of shear key. However, onset points of nonlinearity were difference for different tendon layouts.

Figure 6 shows the deflection along each type of beam at different vertical loads. The relative displacements between the segments (at joint) increased gradually with increase in vertical load. Furthermore, Fig. 7 shows the relative deflection between segments with increase in vertical load. 
Am. J. Engg. \& Applied Sci., 2 (1): 54-60, 2009

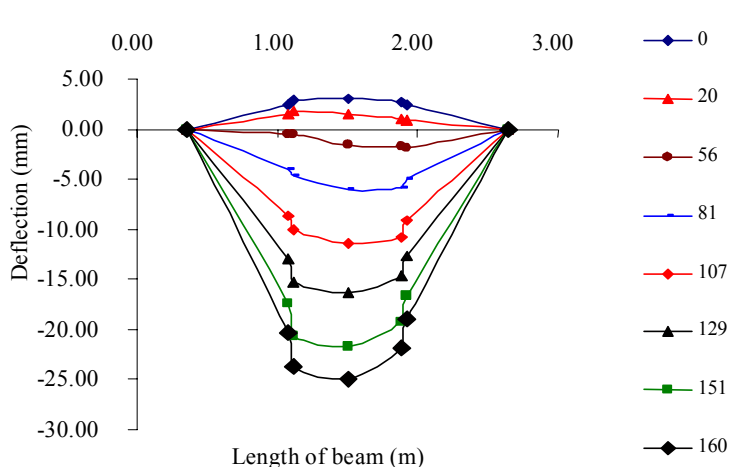

(a) D1

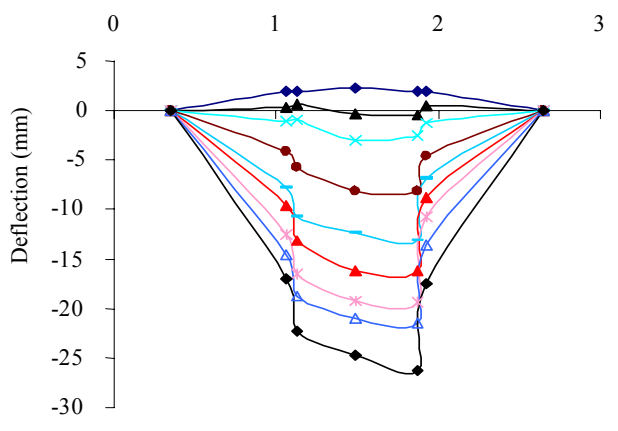

(b) D2

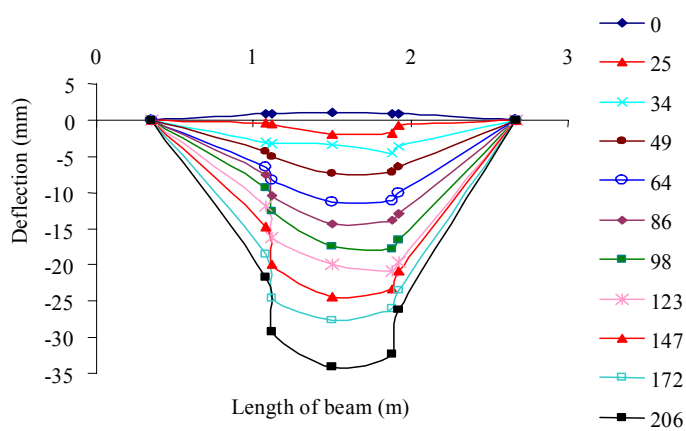

(c) $\mathrm{C} 1$

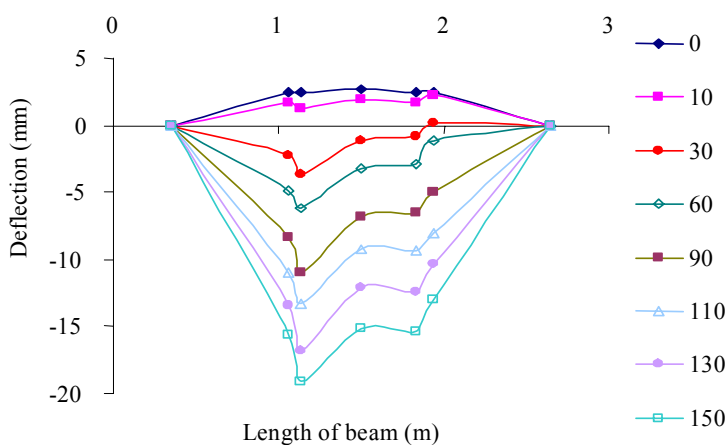

(d) $\mathrm{C} 2$

Fig. 6: Deflection along beams

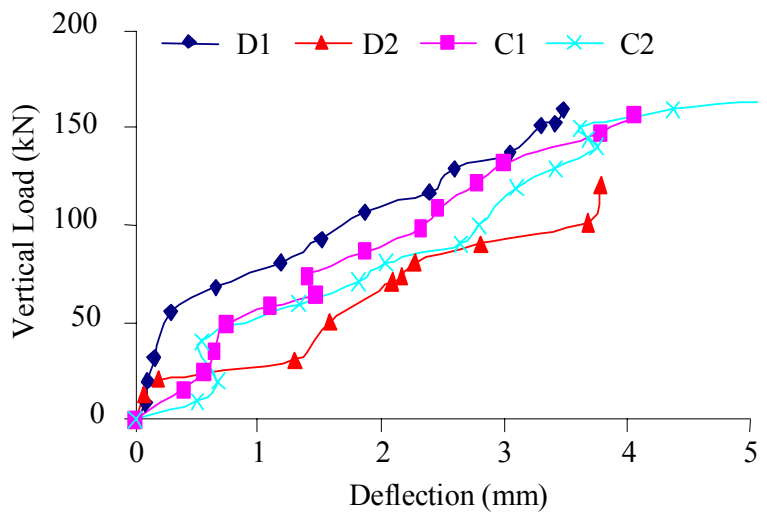

Fig. 7: Relative displacement between segments

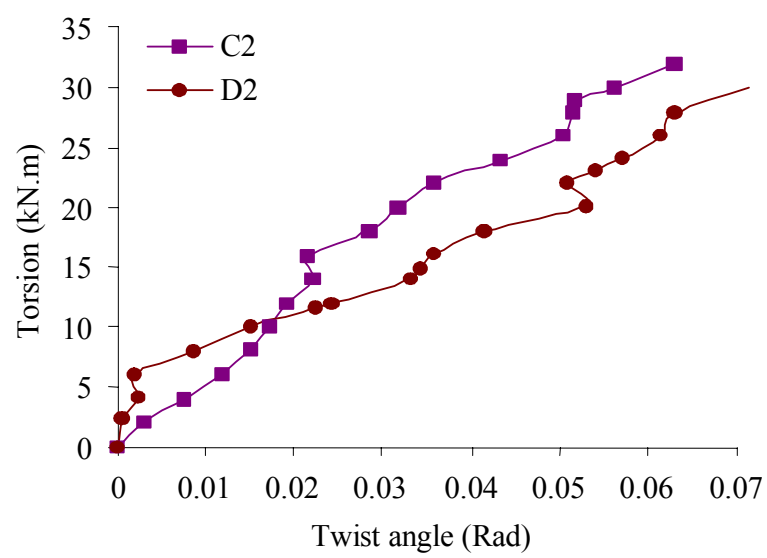

Fig. 8: Relationship of the twist angle of beam with vertical load

The relative deflection at joints increased with increase in torsion. However, in the case of beams D1 and D2 the relative deflections at onset point of nonlinearity and ultimate load were higher than that of the beams C1 and $\mathrm{C} 2$ because of the harp tendon. It can be concluded that the tendon layout has effect on relative deflection.

Figure 8 shows the torsion-twist angle curves of the D2 and C2 beams at mid span. In general the twist angle increased as the torsion increased. Initially twist in beam C2 was lower than that in beam D2. Since beam $\mathrm{C} 2$ did not have any vertical component of the tendon force to resist the applied load, it had higher value of deflection but lower twist angle than D2. The twisting of the middle segment was responsible for failure for the beams with torsion. This occurred as the contact area between the segments reduced due to twisting as well as opening as a result of grow up of tension stress at segment joints.

Tendon strain variation: Figure 9 shows the variation of average strain in the two tendons with applied vertical load (the eccentric load was applied at left side). 


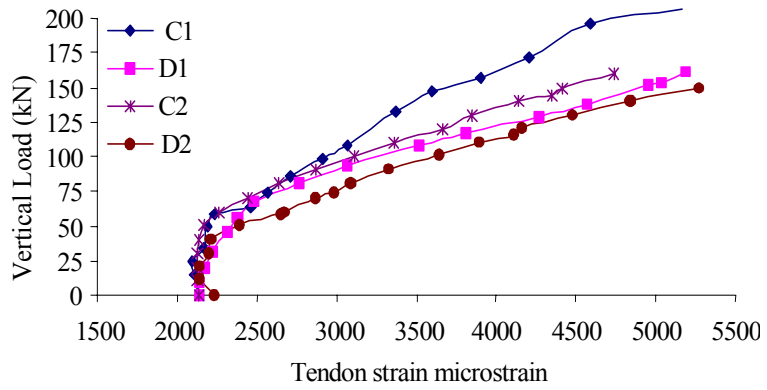

(a) Right side

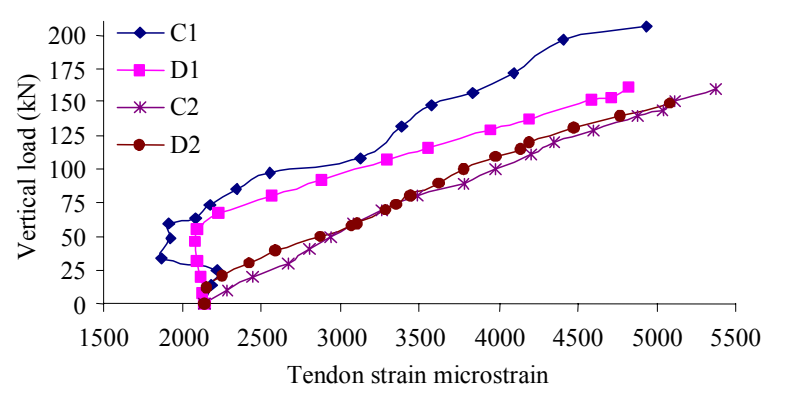

(b) Left side

Fig. 9: Relationship between tendon strain and vertical load

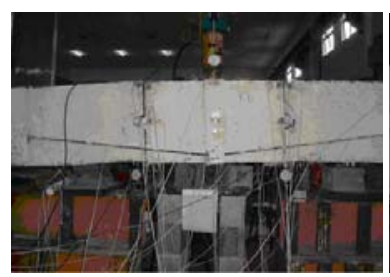

(a) D1

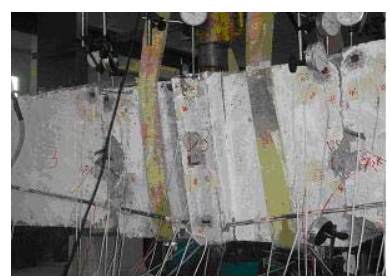

(c) D2

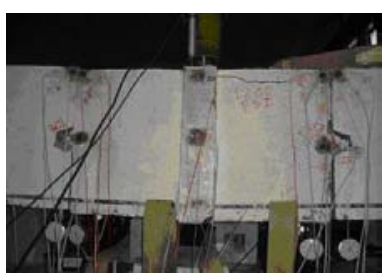

(b) $\mathrm{C} 1$

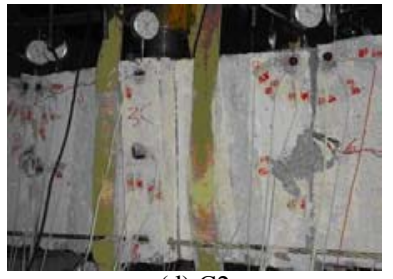

(d) $\mathrm{C} 2$
Fig. 10: Failure mode of beams

Initially the relationship was linear and with further increase in applied load, the response became nonlinear due to redistribution of forces. This was because the tendons got the tension load from the tension zone of segments.

It was observed that the strain behaviour support the load-deflection result. Similar to the load-deflection results, the relationship was linear up to 55 and $20 \mathrm{kN}$ respectively in case of D1 and D2 specimens. After that, with increase in load the tendon strain increased with higher rate till failure. Similarly, for case of $\mathrm{C} 1$ and $\mathrm{C} 2$ specimens, the relationship was linear up to 50 and $10 \mathrm{kN}$ respectively. After that, the strain rate increased with increase in the load until failure.

Furthermore, in both cases (beams C and D) the value of onset point of nonlinearity point decreased with increase in torsion. Moreover, it can be concluded that $\mathrm{C}$ beams had lower tendon strain compared to $\mathrm{D}$ beams.

It was observed that, at the linear portion, the tendon strain decreased due to the reduction of tendon length. This reduction of length was due to the change of the beam curvature from downwards to upwards.

Load capacity: From Fig. 5-9 and Table 2, it can be concluded that, the maximum service load capacities without torsion for $\mathrm{C}$ and $\mathrm{D}$ Specimens were approximately $55 \mathrm{kN}$. However, with the torsion due to eccentricity of $200 \mathrm{~mm}$, the maximum service load capacities of beams decreased up to $60 \%$. Similarly, the ultimate load capacity of the $\mathrm{C}$ beams was approximately $206 \mathrm{kN}$. However, with increasing torsion, the ultimate load capacities decreased up to $37 \%$. Besides, it was also found that no significant difference occurs between the ultimate load capacities for different tendon layouts. However, there was a difference between service load capacities for the different tendon layout.

Failure mode: Figure 10 shows the failure mechanism of $\mathrm{C}$ and $\mathrm{D}$ beams. Initially, with increase in vertical load some small cracks developed near the shear key, anchorages and deviator. After that, the crush cracks developed at the concrete at top of middle segment. The first cracks appeared at the mid span of the middle segment and then it propagated to the joints between segments as shown in Fig. 10.

The failure in the beams without torsion occurred suddenly due to sliding. However, in the beams with torsion a gradual degradation in stiffness due to increase of twist angle was observed.

\section{CONCLUSION}

A number of tests were conducted to study the effect of torsion and tendon layout on the behaviour of externally prestressed segmental concrete box bridge with shear key. The behaviour of the beams was evaluated in terms of vertical deformation, twist angle, opening of segment, tendon strain, load capacity and failure mode.

It was concluded that the opening between segments is the reason behind the nonlinear behaviour of EPS beams. Torsion does not only alters the value of 
failure load, tendon strain and deflection of the beam but it also alters the failure mechanism. Furthermore, due to the shear key, there is a difference between the onset points of nonlinearity load for different tendon layout. In addition, externally prestressed segmental beams with harp tendon layout have better structural characteristics in term of deflection and tendon strain.

\section{ACKNOWLEDGMENTS}

The study conducted as part of this study was cosponsored by the Housing Research Centre and Department of Civil Engineering, University Putra Malaysia.

\section{REFERENCES}

1. AlGorafi, M.A., A.A.A. Ali, M.S. Jaafar and I. Othman, 2007. Performance of segmental prestressed concrete bridges under combined stresses: A critical review. World Engineering Congress, Penang, Malaysia. CS_50:673-680. http://eng.upm.edu.my/wec2007/congressprogram me.pdf

2. Below, K.D., A.S. Hall and B.V. Rangan, 1975. Theory for concrete beams in torsion and bending. ASCE J. Struct. Eng., 101: 1645-1660. http://www.scopus.com/scopus/record/display.url? view $=$ basic\&eid $=2$-s2.0

$0016544632 \&$ origin $=$ reflist\&sort $=$ plfdt$\mathrm{f} \&$ listId $=$ myList $\& \mathrm{src}=\mathrm{s} \& \mathrm{nlo}=\& \mathrm{nlr}=\& \mathrm{nls}=\& \mathrm{imp}=\mathrm{t}$ $\&$ sid $=$ GvuSgeWI6tA3LfXw3RzCoI\%3a570\&sot $=\mathrm{ml} \& \mathrm{sdt}=\mathrm{ml} \& \mathrm{sl}=0$
3. Falkner, H., M. Teutsch and Z. Huang, 1997. Segmentbalken mit vorspannung ohne verbund unter kombinierter beanspruchung aus torsion, biegung und querkraft. J. DAfStb, 472: 7-50. http://www.scopus.com/scopus/results/references.u rl? sort $=\mathrm{cp}-\mathrm{f} \& \mathrm{src}=\mathrm{r} \& \mathrm{imp}=\mathrm{t} \& \mathrm{sid}=\mathrm{GvuSgeWI}$ tA3LfXw3RzCoI\%3a820\&sot=rec\&sdt=citedreferen ces\&sl $=17 \& s=$ CITEID $(543808289) \&$ origin $=$ recor dpage \& citingId $=2$-s $2.0-$ $33645521647 \&$ citeCnt $=1 \&$ txGid $=$ GvuSgeWI6tA3LfXw3RzCoI\%3a82

4. Huang, Z. and X.L. Liu, 2006. Modified skew bending model for segmental bridge with unbonded tendons. J. Bridge Eng., 11: 59-63. DOI:10.1061/(ASCE)1084-0702(2006)11:1(59)

5. Kordina, K., M. Teutsch and V. Weber, 1984. Spannbetonbauteile in segmentbauart under kombinierter beanspruchung aus torsion, biegung und querkraft. J. DafStb, 350: 5-25. http://www.scopus.com/scopus/results/references.u rl? sort $=\mathrm{cp}-\mathrm{f} \& \mathrm{src}=\mathrm{r} \& \mathrm{imp}=\mathrm{t} \& \mathrm{sid}=\mathrm{GvuSgeWI6tA}-$ 3LfXw3RzCoI\%3a820\&sot=rec\&sdt=citedreferen ces\&sl $=17 \& s=$ CITEID (543808289)\&origin $=$ recor dpage \& citingId $=2-\mathrm{s} 2.0-$ $33645521647 \&$ citeCnt $=1 \&$ txGid $=$ GvuSgeWI6tA3LfXw3RzCoI\%3a82.

6. Misic, J. and J. Warwaruk, 1978. Strength of pretsressed solid and hollow beams subjected simultaneously to torsion, shear and bending. ACI J., SP55: 515-545. http://www.concrete.org/PUBS/JOURNALS/Abstr actDetails.asp? ID $=6627$

7. Rabbat, B.G. and K. Solat, 1987. Testing of segmental concrete girders with external tendons. PCI J., 32: 86-107.

http://www.pci.org/publications/journal/back_issue s.cfm?year $=1987$ 